\title{
Analysis of Nonlinear Vibration of Hard Coating Thin Plate by Finite Element Iteration Method
}

\author{
Hui Li, Liu Ying, and Wei Sun \\ School of Mechanical Engineering and Automation, Northeastern University, No. 3-11 Wenhua Road, \\ Heping District, Shenyang 110819, China \\ Correspondence should be addressed to Wei Sun; weisun@mail.neu.edu.cn
}

Received 6 July 2014; Revised 16 September 2014; Accepted 20 September 2014; Published 8 December 2014

Academic Editor: Ahmet S. Yigit

Copyright (C) 2014 Hui Li et al. This is an open access article distributed under the Creative Commons Attribution License, which permits unrestricted use, distribution, and reproduction in any medium, provided the original work is properly cited.

\begin{abstract}
This paper studies nonlinear vibration mechanism of hard coating thin plate based on macroscopic vibration theory and proposes finite element iteration method (FEIM) to theoretically calculate its nature frequency and vibration response. First of all, strain dependent mechanical property of hard coating is briefly introduced and polynomial method is adopted to characterize the storage and loss modulus of coating material. Then, the principle formulas of inherent and dynamic response characteristics of the hard coating composite plate are derived. And consequently specific analysis procedure is proposed by combining ANSYS APDL and self-designed MATLAB program. Finally, a composite plate coated with $\mathrm{MgO}+\mathrm{Al}_{2} \mathrm{O}_{3}$ is taken as a study object and both nonlinear vibration test and analysis are conducted on the plate specimen with considering strain dependent mechanical parameters of hard coating. Through comparing the resulting frequency and response results, the practicability and reliability of FEIM have been verified and the corresponding analysis results can provide an important reference for further study on nonlinear vibration mechanism of hard coating composite structure.
\end{abstract}

\section{Introduction}

The hard coating is a kind of coating materials prepared by the metal, ceramic, or their mixtures, which is mainly used in thermal barrier coatings, antifriction, antierosion, and other engineering application fields. Recently increased attention has been paid to the structural vibration-suppression with hard coating because it can reduce the vibration stress under high temperature or highly corrosive environment [1-3]. Several scholars and researchers [4-6] have experimentally studied the vibration characteristics of thin-walled structures with hard coating, such as beams, plates, and shells; they found that the coating can not only contribute to increasing structural damping as well as reducing the amplitude of resonant vibrations, but also lead to nonlinear characteristics to the coated structure. For example, Ivancic and Palazotto [4] and Blackwell et al. [5] measure inherent characteristic of titanium plate coated with magnesium aluminate spinel, they found that its frequency response curve was not symmetric about resonance frequency at certain mode and the value of resonance frequency decreased with the increase of the amplitude of the applied force, indicating some characteristics of nonlinear stiffness, and they called this phenomenon "strain softening."

Several papers tried to explain the above phenomenon of nonlinear vibration of hard coating composite structure from the scope of mesoscopic elastic materials. For example, Tassini et al. [7] implemented a phenomenological model that characterizes nonlinear mesoscopic elastic materials, which is capable of reproducing the basic features of the observed damping behavior for zirconia coatings prepared by air plasma spraying and electron-beam physical-vapordeposition. Green and Patsias [8] proposed a friction model to calculate the response of a coated beam and obtain the variation of damping effectiveness for several vibration modes. Torvik [9] developed a slip damping model, incorporating both microslip and macroslip in providing qualitative predictions of the amplitude dependence of the dissipation in a lap joint, and the damping (loss modulus) was also extracted, and the amplitude dependence was found to be similar to that observed with actual coating materials. Al-Rub and Palazotto [10] proposed a micromechanical theoretical and 
computational model to assess the main micromechanical mechanisms responsible for the experimentally observed nonlinear vibration in plasma sprayed hard ceramic coatings. These studies have contributed a lot to the understanding of energy dissipation mechanism of hard coating as well as the related nonlinear vibration of composite structure.

However, it is not realistic to completely understand nonlinear vibration characteristics of hard coating composite structure from microscopic scope; in order to effectively implement damping coating technique for vibration suppression, it is necessary to develop mechanical model in accordance with macrovibration theory. Unfortunately, research efforts spent in this area are not adequate enough because it is still a challenge to present a reliable model to describe the mechanical properties of hard coating composite structure when the observed response is that of a nonlinear system, which have generally been found to display a strong dependence on the amplitude of strain. Besides, another challenge is to identify mechanical parameters of the coating, such as strain dependent Young's modulus and the loss modulus, which are mainly responsible for nonlinearity of the coated structure. Fortunately, several papers have made some progress in identifying such parameters. Patsias et al. [11] tested Nimonic C-263 beam specimen coated with aluminium oxide under different excitation levels and proposed an experimental procedure for extracting the coating's damping (internal friction) and the modulus of elasticity with the variation of strain from response decays. Torvik [12] presented a methodology suitable for determining the amplitude-dependent mechanical properties of coating applied on substrate beams, and its storage (Young's) modulus, the loss modulus, and the loss factor can be extracted by careful measurement of specimen dimensions, weights, nature frequencies, and loss factors before and after coating. Reed et al. [13] set up a novel vibration experiment system and proposed an experimental technique for accurate measurement of strain dependent stiffness and damping properties of hard coatings at high strain levels, which provided an important support for modeling coating composite structure and its nonlinear vibration analysis.

Finite element iteration technique is an efficient and practical method, which can be used to solve vibration problems with considering variable mass, stiffness, and damping in the kinetic equation. For example, Hernandez and Bernal [14] adopted an iterative time domain formulation for finite element model to update the stiffness and damping parameters of a twenty-degree-of-freedom shear beam. Hu et al. [15] considered the contact between drillstring and borehole and proposed an iterative finite element technology to analyze drillstring dynamic. Soares [16] presented an optimised FEMBEM iterative coupling algorithm and demonstrated the effectiveness on an elastodynamic rectangular rod and a circular cavity. Filippi and Torvik [17] proposed iterative finite element analysis method to predict the response of an actual blade with a nonlinear coating, which can be used to quickly determine the approximate resonant frequency, damping, and response amplitude in the vicinity of a particular resonance. However, linear analytic expressions are used for the nonlinear coating material and the structural damping is expressed by loss factor, which may help in getting damping matrix in uniform form, but fails to separate viscous damping from loss factor of the material. Therefore, if we can effectively express strain dependent mechanical parameters of hard coating and consequently introduce them into the finite element equation to solve the nodal displacements in the equation by numerical iteration method, it would be a good solution to theoretical analysis of the concerned nonlinear dynamics mechanism of hard coating composite structure.

This paper studies nonlinear vibration mechanism of hard coating thin plate based on macroscopic vibration theory and proposes finite element iteration method (FEIM) to theoretically calculate its nature frequency and vibration response. In Section 2, strain dependent mechanical property of hard coating is briefly introduced and polynomial method is adopted to characterize the storage and loss modulus of coating material. Then go on to theoretically derive the principle formulas of inherent and dynamic response characteristics of the hard coating composite plate in Section 3 and consequently propose specific analysis procedure by combining ANSYS APDL and self-designed MATLAB program in Section 4. Finally in Section 5, a composite plate coated with $\mathrm{MgO}+\mathrm{Al}_{2} \mathrm{O}_{3}$ is taken as a study object and both nonlinear vibration test and analysis are conducted on the plate specimen with considering strain dependent mechanical parameters of hard coating. Through comparing the resulting frequency and response results, the practicability and reliability of FEIM have been verified and the corresponding analysis results can provide an important reference for further study on nonlinear vibration mechanism of hard coating composite structure.

\section{Polynomial Characterization of Strain Dependent Mechanical Parameters of Hard Coating}

Suppose that $E_{c}^{*}$ can be used to represent elastic modulus of hard coating, which is defined as complex modulus:

$$
E_{c}^{*}=E_{c}^{\prime}\left(\varepsilon_{e}\right)+i E_{c}^{\prime \prime}\left(\varepsilon_{e}\right),
$$

where “*” refers to complex; $E_{c}^{\prime}\left(\varepsilon_{e}\right), E_{c}^{\prime \prime}\left(\varepsilon_{e}\right)$ are storage modulus (or Young's modulus) and loss modulus, respectively, and they are all functions of equivalent strain $\varepsilon_{e}$.

For simplicity, we can adopt polynomial method to characterize $E_{c}^{\prime}\left(\varepsilon_{e}\right)$ and $E_{c}^{\prime \prime}\left(\varepsilon_{e}\right)$, which can be expressed as

$$
\begin{aligned}
& E_{c}^{\prime}\left(\varepsilon_{e}\right)=E_{R 0}+\varepsilon_{e} E_{R 1}+\varepsilon_{e}^{2} E_{R 2}+\varepsilon_{e}^{3} E_{R 3}+\cdots, \\
& E_{c}^{\prime \prime}\left(\varepsilon_{e}\right)=E_{I 0}+\varepsilon_{e} E_{I 1}+\varepsilon_{e}^{2} E_{I 2}+\varepsilon_{e}^{3} E_{I 3}+\cdots,
\end{aligned}
$$

where $E_{R 0}, E_{I 0}$ are the storage and loss modulus without considering strain dependence and $E_{R n}, E_{I n}(n=1,2,3, \ldots)$ are the specific coefficients of strain dependent storage modulus and loss modulus.

Substituting (2) into (1) and elastic modulus of hard coating, $E_{c}^{*}$ can be expressed as

$$
E_{c}^{*}=E_{c 0}^{*}+E_{c 1}^{*} \varepsilon_{e}+E_{c 2}^{*} \varepsilon_{e}^{2}+E_{c 3}^{*} \varepsilon_{e}^{3}+\cdots,
$$

where $E_{c 0}^{*}=E_{R 0}+i E_{I 0}$ and $E_{c n}^{*}=E_{R n}+i E_{I n}, n=1,2,3, \ldots$. 


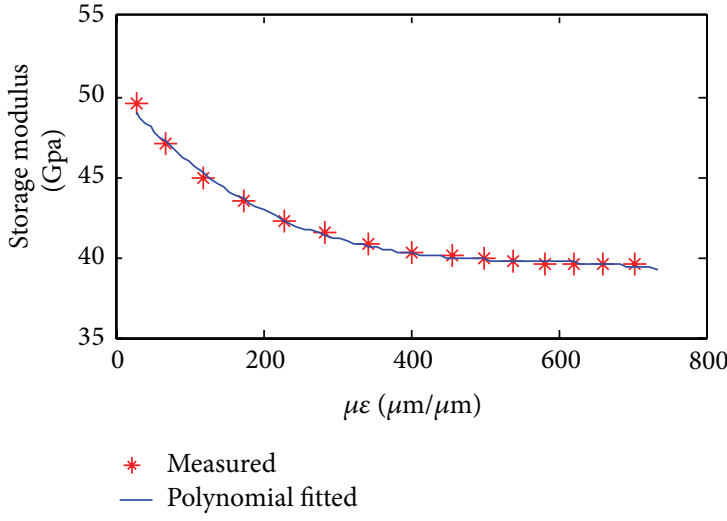

(a) Storage modulus

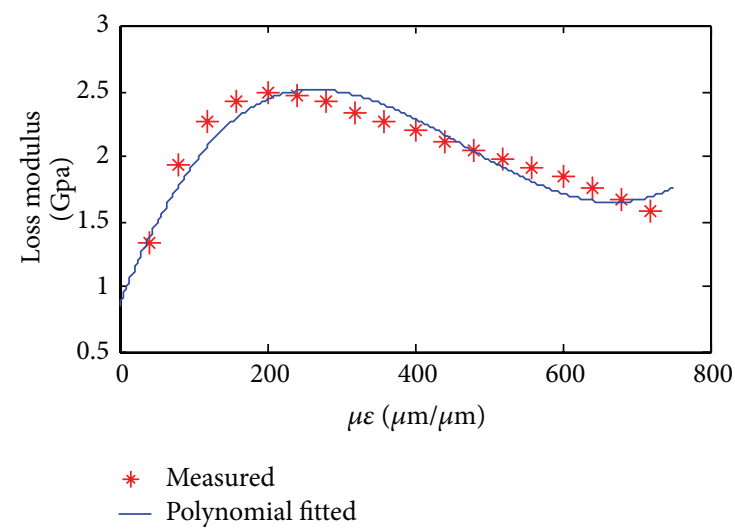

(b) Loss modulus

Figure 1: Mechanical parameters of $\mathrm{MgO}+\mathrm{Al}_{2} \mathrm{O}_{3}$ with strain dependent characteristics.

Usually mechanical parameters of hard coating can be identified by some experimental method, which are mainly dependent on the amplitude of strain; that is, strain amplitudes and modulus values are corresponding to each other. In an effort to effectively express their relationship, it is necessary to adopt polynomial fitting technique. As reference [13] has already experimentally determined discrete storage modulus and loss modulus of coating material such as $\mathrm{MgO}+$ $\mathrm{Al}_{2} \mathrm{O}_{3}$, as seen in Figures 1(a) and 1(b), we can calculate the explicit expressions by curve-fitting of cube polynomial. The resulting mathematical expressions are given in (4) and (5), and the fitted curves are also plotted in Figures 1(a) and 1(b), respectively.

$$
\begin{aligned}
E_{c}^{\prime}(\varepsilon)= & 50.439-0.05386 \varepsilon_{e} \\
& +9.2396 \times 10^{-5} \varepsilon_{e}^{2}-5.4190 \times 10^{-8} \varepsilon_{e}^{3}, \\
E_{c}^{\prime \prime}(\varepsilon)= & 0.9122+0.01321 \varepsilon_{e} \\
& -3.2997 \times 10^{-5} \varepsilon_{e}^{2}+2.2086 \times 10^{-8} \varepsilon_{e}^{3} .
\end{aligned}
$$

\section{Nonlinear Vibration Analysis Principle of Hard Coating Composite Plate by FEIM}

The finite element equation of hard coating composite structure, such as beams, plates, and shells with different kinds of materials covered on the surface, can be expressed as

$$
\mathbf{M} \ddot{\mathbf{x}}+\mathbf{C} \dot{\mathbf{x}}+\mathbf{K}^{*} \mathbf{x}=\mathbf{F},
$$

where $\mathbf{M}, \mathbf{C}$, and $\mathbf{K}^{*}$ are mass matrix, damping matrix, and complex stiffness matrix of the physical system and $\mathbf{F}$ is external excitation force vector; $\mathbf{x}, \dot{\mathbf{x}}$, and $\ddot{\mathbf{x}}$ are nodal displacement, velocity, and acceleration vector in physical coordinate, respectively. Additionally, $\mathbf{K}^{*}=\mathbf{K}+i \mathbf{D}$, where $\mathbf{K}$ represents the real part of the complex stiffness matrix and $\mathbf{D}$ is material damping matrix.

Due to strain dependence characteristic, complex stiffness matrix $\mathbf{K}^{*}$ in (6) requires special consideration. Besides, because each finite element is related to different strain states, it is necessary to calculate each element stiffness matrix and combine them to get the global stiffness matrix, which can be expressed as

$$
\begin{array}{r}
\mathbf{K}^{*}=\mathbf{K}_{0}^{*}+\sum_{n}^{N} \frac{\mathbf{K}_{n, 0}\left(E_{c 1}^{*} \varepsilon_{e, n}+E_{c \varepsilon^{2}}^{*} \varepsilon_{e, n}^{2}+E_{c 3}^{*} \varepsilon_{e, n}^{3}\right)}{E_{R, 0}} \\
(n=1,2,3, \ldots, N),
\end{array}
$$

where $\mathbf{K}_{0}^{*}$ are the global stiffness matrix without considering strain dependence, $\varepsilon_{e, n}$ is equivalent strain of the $n$th element of composite plate, $E_{c 1}^{*}, E_{c 2}^{*}$, and $E_{c 3}^{*}$ can be obtained from (3) by polynomial fitting technique, and $\mathbf{K}_{n, 0}$ is stiffness matrix with the $\varepsilon_{e, n}=0$.

According to definition of strain energy density, equivalent strain of the $n$th element of composite plate, $\varepsilon_{e, n}$, can be expressed as

$$
\varepsilon_{e, n}=\sqrt{\mathbf{x}^{T} \frac{\mathbf{K}_{n, 0}}{E_{R, 0} V_{n}} \mathbf{x}}
$$

where $T$ represents the transpose operation and $V_{n}$ is the volume of the $n$th element.

Suppose that modal analysis theory still can be used to solve (6) considering strain dependence of hard coating, and normal mode shape matrix always indicates constant value for the different strain states of composite plate; thus the relation between physical coordinates and normal coordinates can be expressed as

$$
\mathbf{x}=\Phi_{N} \mathbf{q}
$$

where $\mathbf{q}$ is the response in normal coordinate and $\boldsymbol{\Phi}_{N}$ is normal mode shape matrix, which can be obtained from the following equation:

$$
\boldsymbol{\Phi}_{N}^{T} \mathbf{M} \boldsymbol{\Phi}_{N}=\mathbf{I},
$$

where I refers to identity matrix and its dimension is equal to that of $\mathbf{M}$. 
Substitute (9) into (8); $\varepsilon_{e, n}$ can be further simplified as

$$
\begin{gathered}
\varepsilon_{e, n}=\sqrt{\frac{\mathbf{q}^{T} \mathbf{h}_{n} \mathbf{q}}{V_{n}}}, \\
\mathbf{h}_{n}=\frac{\boldsymbol{\Phi}_{N}^{T} \mathbf{K}_{n, 0} \boldsymbol{\Phi}_{N}}{E_{R, 0}} .
\end{gathered}
$$

By transforming (6) using normal mode shape matrix $\Phi_{N}$, the resulting motion equation can be expressed as

$$
\begin{gathered}
\left(\mathbf{K}_{N}^{*}+i \omega \mathbf{C}_{N}-\omega^{2} \mathbf{I}\right) \mathbf{q}=\mathbf{F}_{N} \\
\mathbf{K}_{N}^{*}=\boldsymbol{\Phi}_{N}^{T} \mathbf{K}^{*} \boldsymbol{\Phi}_{N} \\
=\mathbf{K}_{0 N}^{*}+\sum_{n}^{N} \frac{\boldsymbol{\Phi}_{N}^{T} \mathbf{K}_{n, 0} \boldsymbol{\Phi}_{N}}{E_{R, 0}} \\
\times\left(E_{c 1}^{*} \varepsilon_{e, n}+E_{c 2}^{*} \varepsilon_{e, n}^{2}+E_{c 3}^{*} \varepsilon_{e, n}^{3}\right) \\
\mathbf{K}_{0 N}^{*}=\boldsymbol{\Phi}_{N}^{T} \mathbf{K}_{0}^{*} \boldsymbol{\Phi}_{N}, \quad \mathbf{C}_{N}=\boldsymbol{\Phi}_{N}^{T} \mathbf{C} \boldsymbol{\Phi}_{N}, \quad \mathbf{F}_{N}=\boldsymbol{\Phi}_{N}^{T} \mathbf{F},
\end{gathered}
$$

where $\omega$ refers to excitation angular frequency, $\mathbf{K}_{N}^{*}$ refers to complex stiffness matrix in normal coordinate, and $\mathbf{C}_{N}$ refers to damping matrix in normal coordinate. It should be noted that usually the damping matrix $\mathbf{C}_{N}$ cannot be diagonalized by the same transformation that diagonalizes the mass matrix $\mathbf{M}$ or stiffness matrix $\mathbf{K}_{0 N}^{*}$. But damping matrix $\mathbf{C}_{N}$ can often be regarded as viscous damping matrix as long as the $k$ th damping ratio of hard coating composite structure is less than 0.2 . In this case, the physical system can be considered a "weak damped system," and damping matrix $\mathbf{C}_{N}$ can be diagonalized by the $k$ th nature frequency and $k$ th damping ratio (we will discuss how to bring the tested damping results into this system in Section 4.2 in detail).

In order to solve nature frequencies of hard coating composite plate, the following equation can be used as the principle formula for iterative solution:

$$
\left|R\left(\mathbf{K}_{N}^{*}\right)-\omega_{n}^{2} \mathbf{I}\right|=0
$$

where operator $R()$ refers to getting the real part of an expression in the bracket notation and $\omega_{n}$ is the $n$th nature frequency (circular frequency).

When the 2-norm of the difference between nature frequency, $\omega_{n}^{(j+1)}$ at the $j+1$ th time and $\omega_{n}^{(j)}$ at the $j$ th time meets the following equation, we can finally determine $\omega_{n}$ by setting appropriate iteration termination condition in (17), whose calculation procedure will be described in detail in Section 4.1. Consider

$$
\left\|\omega_{n}^{(j+1)}-\omega_{n}^{(j)}\right\|_{2} \leq S_{0},
$$

where $S_{0}$ is the accuracy factor for iteration calculation.

By solving (16) with iteration technique, we can already calculate nature frequency of coated structure. Next, we can further calculate its vibration response such as node displacement with considering strain dependence of hard coating, which can be regarded as searching for solutions of (13). Here, Newton-Raphson iteration method is employed, and through transposition treatment, we get the following expression:

$$
\begin{aligned}
\mathbf{r}= & \left(\mathbf{K}_{N}^{*}+i \omega \mathbf{C}_{N}-\omega^{2} \mathbf{I}\right) \mathbf{q}-\mathbf{F}_{N} \\
= & \left(\mathbf{K}_{0 N}^{*}+i \omega \mathbf{C}_{N}-\omega^{2} \mathbf{I}\right) \mathbf{q}-\mathbf{F}_{N} \\
& +E_{c 1}^{*} \sum_{n}^{N} \sqrt{\frac{\mathbf{q}^{T} \mathbf{h}_{n} \mathbf{q}_{n}}{V_{n}}} \mathbf{h}_{n} \mathbf{q}+E_{c 2}^{*} \sum_{n}^{N} \frac{\mathbf{q}^{T} \mathbf{h}_{n} \mathbf{q}_{n}}{V_{n}} \mathbf{q} \\
& +E_{c 3}^{*} \sum_{n}^{N}\left(\frac{\mathbf{q}^{T} \mathbf{h}_{n} \mathbf{q}}{V_{n}}\right)^{3 / 2} \mathbf{h}_{n} \mathbf{q},
\end{aligned}
$$

where $\mathbf{r}$ is the residual vector.

Because $\mathbf{r}$ is a complex vector, it is relatively difficult to solve this complex vector by some traditional techniques. For the reliable accuracy, it is necessary to separate the real and imaginary part of $\mathbf{r}$, and a similar separation is done on $\mathbf{q}$ and the Jacobian matrix $\mathbf{J}$, whose solving equation with separated real and imaginary part can be expressed as

$$
\begin{gathered}
\mathbf{J}=\left[\begin{array}{cc}
R\left(\frac{\partial \mathbf{r}}{\partial \mathbf{q}_{R}}\right) & R\left(\frac{\partial \mathbf{r}}{\partial \mathbf{q}_{I}}\right) \\
I\left(\frac{\partial \mathbf{r}}{\partial \mathbf{q}_{R}}\right) & I\left(\frac{\partial \mathbf{r}}{\partial \mathbf{q}_{I}}\right)
\end{array}\right] \\
\frac{\partial \mathbf{r}}{\partial \mathbf{q}_{R}}=\mathbf{K}_{0 N}^{*}+i \omega \mathbf{C}_{N}-\omega^{2} \mathbf{I} \\
+\sum_{n}^{N}\left(\left(\frac{E_{c 1}^{*}}{V_{n} \varepsilon_{n}}+\frac{2 E_{c 2}^{*}}{V_{n}}+\frac{3 E_{c 3}^{*} \varepsilon_{n}}{V_{n}}\right) \mathbf{h}_{n} \mathbf{q} R\left(\mathbf{h}_{n} \mathbf{q}\right)^{T}\right)
\end{gathered}
$$

$$
\begin{aligned}
\frac{\partial \mathbf{r}}{\partial \mathbf{q}_{I}}= & i\left(\mathbf{K}_{0 N}^{*}+i \omega \mathbf{C}_{N}-\omega^{2} \mathbf{I}\right) \\
& +\sum_{n}^{N}\left(\left(\frac{E_{c 1}^{*}}{V_{n} \varepsilon_{n}}+\frac{2 E_{c 2}^{*}}{V_{n}}+\frac{3 E_{c 3}^{*} \varepsilon_{n}}{V_{n}}\right) \mathbf{h}_{n} \mathbf{q} I\left(\mathbf{h}_{n} \mathbf{q}\right)^{T}\right),
\end{aligned}
$$

where $\mathbf{q}_{R}$ and $\mathbf{q}_{I}$ are the real and imaginary part of the response in normal coordinate, respectively, and operator $I()$ refers to getting the imaginary part of an expression in the bracket notation.

Then, by using Newton-Raphson iteration method, the iteration formula of (18) can be expressed as following:

$$
\begin{aligned}
& \overline{\mathbf{r}}^{(j)}+\mathbf{J}^{(j)} \cdot \Delta \overline{\mathbf{q}}^{(j)}=\mathbf{0}, \\
& \overline{\mathbf{q}}^{(j+1)}=\overline{\mathbf{q}}^{(j)}+\Delta \overline{\mathbf{q}}^{(j)},
\end{aligned}
$$

where $\Delta \overline{\mathbf{q}}^{(j)}$ is response increment at the $j$ th time (superscript $j$ or $j+1$ represents different iteration calculation times), and 
$\overline{\mathbf{r}}$ and $\overline{\mathbf{q}}$ are the separation vectors of $\mathbf{r}$ and $\mathbf{q}$, which can be expressed as following:

$$
\begin{aligned}
& \overline{\mathbf{r}}=\left\{\begin{array}{c}
R(\mathbf{r}) \\
I(\mathbf{r})
\end{array}\right\}, \\
& \overline{\mathbf{q}}=\left\{\begin{array}{l}
R(\mathbf{q}) \\
I(\mathbf{q})
\end{array}\right\} .
\end{aligned}
$$

In (22) and (23), we can determine its iteration termination by calculating 2 -norm of residual vector $\overline{\mathbf{r}}$ with separated real and imaginary part, which can be expressed as following:

$$
\|\overline{\mathbf{r}}\|_{2}=\sqrt{\left(\left|\bar{r}_{1}\right|^{2}+\left|\bar{r}_{2}\right|^{2}+\left|\bar{r}_{3}\right|^{2}+\cdots\right)} \leq S_{0} .
$$

When the above termination condition is achieved (e.g., set accuracy factor for iteration calculation $S_{0}=0.001$ ), we can obtain $\overline{\mathbf{q}}$. Then, adopt the following equation to restore it into complex vector, and bring $\mathbf{q}$ to (9), and the concerned node displacement, $\mathbf{x}$, can be completely obtained. Consider

$$
\mathbf{q}=R(\mathbf{q})+i I(\mathbf{q})
$$

\section{Nonlinear Vibration Analysis Procedure of Hard Coating Composite Plate by FEIM}

In this section, based on the deep understanding of principle formulas associated with finite element iteration method in Section 3, by taking an example of thin plate specimen coated with $\mathrm{MgO}+\mathrm{Al}_{2} \mathrm{O}_{3}$, analysis procedure of nature frequency and vibration response of hard coating composite plate are proposed, which combine ANSYS APDL program with selfdesigned MATLAB program, and can be summarized as follows:

(1) firstly write APDL program to calculate and extract mass matrix, damping matrix, stiffness matrix, and external excitation force vector of coated structure;

(2) secondly write finite element iteration program based on MATLAB to obtain equivalent strain of each element $\varepsilon_{e, n}$, and consequently get complex modulus $E_{c}^{*}$ by the known mechanical parameters of $\mathrm{MgO}+$ $\mathrm{Al}_{2} \mathrm{O}_{3}$ obtained by curve-fitting of cube polynomial;

(3) finally obtain complex stiffness matrix in normal coordinate $\mathbf{K}_{N}^{*}$, with considering strain dependent mechanical parameters of hard coating, and thus nature frequency and vibration response can be iteratively calculated by setting appropriate iteration termination condition.

4.1. Analysis Procedure of Nature Frequency. In order to calculate nature frequencies of hard coating composite plate, the following analysis procedure is proposed, as seen in Figure 2(a), some of the key steps need to be illustrated as follow.

(1) Extract Mass Matrix, Damping Matrix, Stiffness Matrix, and External Excitation Force Vector of Composite Plate. Calculating and extracting mass matrix, damping matrix, stiffness matrix, and external excitation force vector of composite plate is the basis for analyzing its inherent and dynamic response characteristics, and this step is accomplished using APDL program. Firstly, input dimension parameters of composite plate, such as length, width, and thickness of the substrate plate and the coating. Then, input the related mechanical parameters without considering strain dependence, such as the density, Poisson's ratio, storage (Young's) modulus, and the loss factor (noting that the coating's loss factor is the ratio of loss modulus in (5) to storage modulus in (4) with the strain $\varepsilon_{e}=0$ ). Next, establish the finite element model of coated plate and apply external excitation load and boundary condition to the model to carry out finite element modal analysis by QR damping method. It should be noted that, for the sake of convenient extraction of excitation force vector (called nodal load vector) from ANSYS, it is necessary to apply external excitation load to the model; this load could be single-point or multipoint excitation force or base excitation. In this example, clamped-free boundary condition and base excitation are chosen because they will not bring additional quality to the coated plate and it is relatively easy to verify such finite element model by experimental test method. At last, by outputting in the form of text, mass matrix, damping matrix, stiffness matrix, and external excitation force vector of composite plate can be obtained.

(2) Calculate Iteration Initial Value of Nature Frequency, Normal Mode Shape Matrix, and Normal Force. In this step, iteration initial value of nature frequency, $\widetilde{\omega}_{n}$, is obtained by (28) on the premise that strain dependence characteristic of the coating has not been considered. Additionally, normal mode shape matrix, $\Phi_{N}$, can be obtained by performing operation on mass matrix $\mathbf{M}$ in (10), and normal force $\mathbf{F}_{N}$ can be calculated by (15). It should be noted that this and the following steps are all accomplished by the self-designed MATLAB program

$$
\left|\mathbf{K}-\widetilde{\omega}_{n}^{2} \mathbf{M}\right|=0
$$

(3) Calculate Iteration Initial Value of Resonant Response in Normal Coordinate. In this step, iteration initial value of resonant response in normal coordinate, $\widetilde{\mathbf{q}}$, is obtained by (29) on the same premise that strain dependence characteristic of the coating has not been considered, and $\widetilde{\omega}_{n}$ can be obtained from step (1) and $\mathbf{K}_{0 N}^{*}$ can be obtained by performing operation on the global stiffness matrix, $\mathbf{K}_{0}^{*}$, in (15). Thus, select a certain nature frequency which needs to be iteratively calculated in the following steps, and by using (29) we can obtain the corresponding iteration initial value of resonant response $\widetilde{\mathbf{q}}$

$$
\left(\mathbf{K}_{0 N}^{*}-\widetilde{\omega}_{n}^{2} \mathbf{I}\right) \widetilde{\mathbf{q}}=\mathbf{F}_{N} .
$$

(4) Calculate Equivalent Strain of Each Element and Complex Stiffness Matrix of Composite Plate. In this step, because iteration initial value of resonant response, $\widetilde{\mathbf{q}}$, has already been obtained, we can further substitute $\mathbf{q}=\widetilde{\mathbf{q}}$ into (11) and combine this equation with (12); thus equivalent strain of each element of coated plate, $\varepsilon_{e, n}$, can be calculated. 


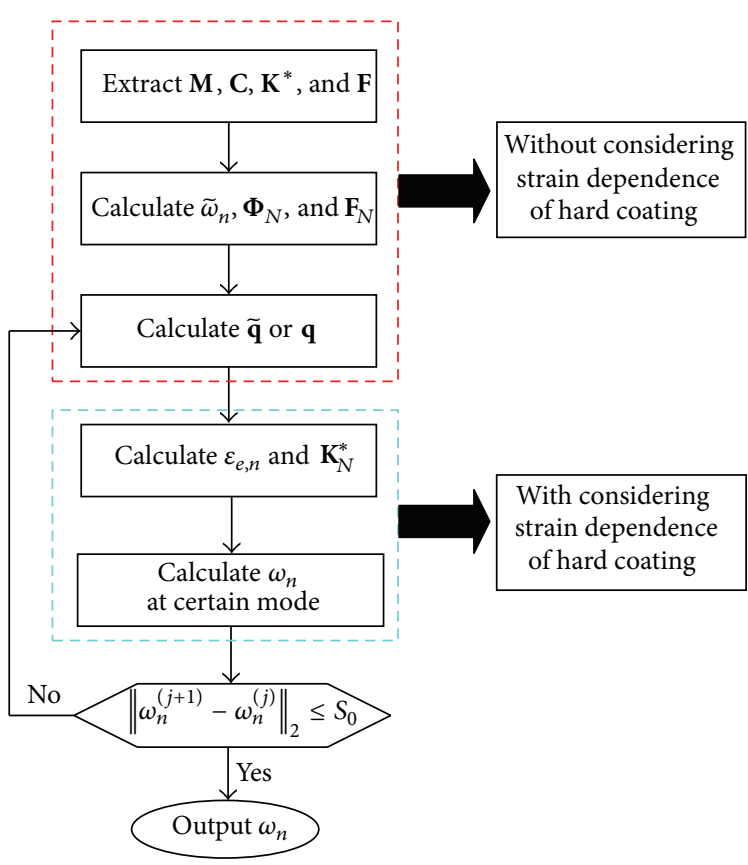

(a) Analysis procedure of nature frequency

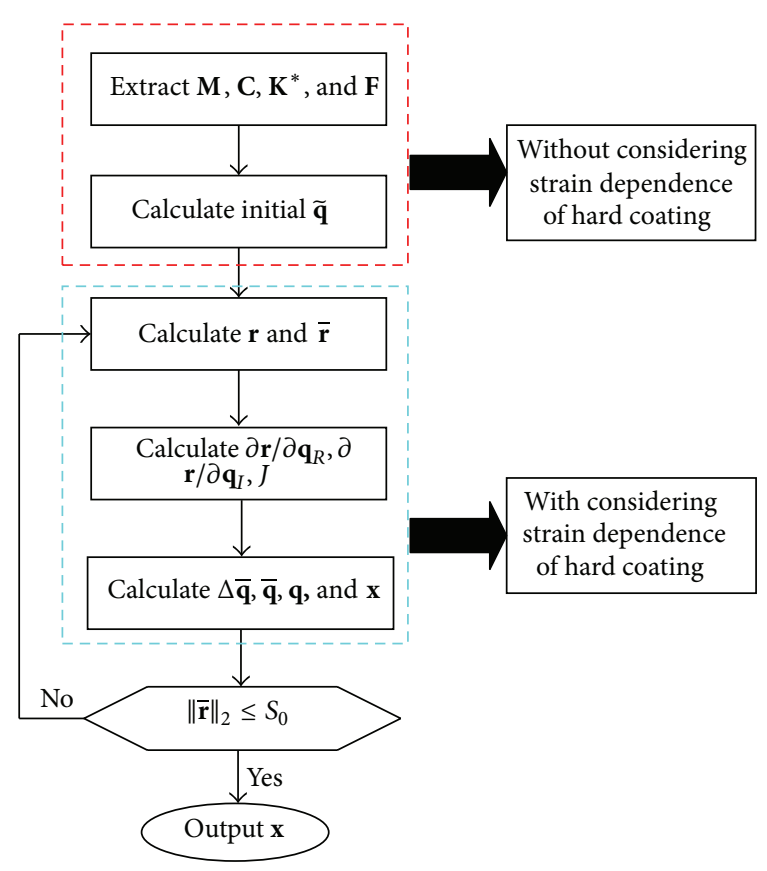

(b) Analysis procedure of vibration response

FIGURE 2: Nonlinear vibration analysis procedure of hard coating composite plate by FEIM.

Next, get complex modulus $E_{c}^{*}$ by the known mechanical parameters of $\mathrm{MgO}+\mathrm{Al}_{2} \mathrm{O}_{3}$ obtained by curve-fitting of cube polynomial. Then, bring $\varepsilon_{e, n}$ and $E_{c}^{*}$ into (14) and complex stiffness matrix in normal coordinate and $\mathbf{K}_{N}^{*}$ can be calculated with considering strain dependent mechanical parameters of hard coating, which is a critical step in making sure that iteration calculation of nature frequency can be successfully conducted.

(5) Iteratively Calculate Nature Frequency of Composite Plate. In this step, in the effort to iteratively calculate $n$th nature frequency $\omega_{n}$ associated with the acquired complex stiffness matrix $\mathbf{K}_{N}^{*}$ in (16), it is necessary to set appropriate accuracy factor for iteration calculation $S_{0}$. If the resulting $\omega_{n}$ do not meet the requirement of $S_{0}$, it is needed to recalculate resonant response $\mathbf{q}$ by using $\omega_{n}$ as the excitation frequency. By carefully comparing calculation results, when $S_{0}$ is equal to 0.001 , it is accurate enough to determine $\omega_{n}$ and its calculation efficiency is relatively satisfying. Finally, by repeating step (3) to step (5), the first five or more nature frequencies can be sequentially obtained.

4.2. Analysis Procedure of Vibration Response. In order to calculate vibration response of hard coating composite plate, the following analysis procedure is proposed; as seen in Figure 2(b), some of the key steps need to be illustrated as follows.

(1) Extract Mass Matrix, Damping Matrix, Stiffness Matrix, and External Excitation Force Vector of Composite Plate. The step has been discussed in Section 4.1 in detail.
(2) Calculate Iteration Initial Value of Vibration Response in Normal Coordinate. In this step, iteration initial value of vibration response in normal coordinate, $\widetilde{\mathbf{q}}$, is obtained on the premise that strain dependence characteristic of the coating has not been considered. Firstly, use the extracted mass matrix, damping matrix, stiffness matrix, and external excitation force vector in step (1) to calculate the related matrix in normal coordinate. Then, choose excitation frequency $\omega$ to get the corresponding iteration initial value of vibration response $\widetilde{\mathbf{q}}$ by the following equation:

$$
\left(\mathbf{K}_{0 N}^{*}+i \omega \mathbf{C}_{N}-\omega^{2} \mathbf{I}\right) \widetilde{\mathbf{q}}=\mathbf{F}_{N},
$$

where $\mathbf{K}_{0 N}^{*}, \mathbf{C}_{N}$, and $\mathbf{F}_{N}$ can be obtained by performing operation on $\mathbf{K}_{0}^{*}, \mathbf{C}$, and $\mathbf{F}$ in (15). Because damping matrix $\mathbf{C}_{N}$ is regarded as viscous damping matrix without considering strain dependence of hard coating which is approximately equal to the corresponding damping matrix of uncoated plate structure, it is actually a diagonal matrix and its expression in the $k$ th row and $k$ th column can be approximately written as

$$
\mathrm{C}_{N}(k, k) \approx 2 \omega_{k}^{\prime} \zeta_{k}^{\prime}
$$

where $\omega_{k}^{\prime}$ and $\zeta_{k}^{\prime}$ are the $k$ th nature frequency and $k$ th damping ratio of uncoated plate, respectively, which can be accurately measured by experimental test.

(3) Calculate Residual Vector and Separate Its Real and Imaginary Part. Calculating and converting residual vector to get the separated real and imaginary part is a critical step in making sure that iteration calculation of vibration response can be successfully conducted, because it is necessary to 
TABLE 1: The geometry parameters and material parameters of the composite plate.

\begin{tabular}{lcccccccc}
\hline Name & Material Type & $\begin{array}{c}\text { Free length } \\
(\mathrm{mm})\end{array}$ & $\begin{array}{c}\text { Clamping } \\
\text { length }(\mathrm{mm})\end{array}$ & $\begin{array}{c}\text { Width } \\
(\mathrm{mm})\end{array}$ & $\begin{array}{c}\text { Thickness } \\
(\mathrm{mm})\end{array}$ & $\begin{array}{c}\text { Density } \\
\left(\mathrm{kg} / \mathrm{m}^{3}\right)\end{array}$ & $\begin{array}{c}\text { Young's } \\
\text { modulus }(\mathrm{GPa})\end{array}$ & $\begin{array}{c}\text { Poisson's } \\
\text { ratio }\end{array}$ \\
\hline Substrate plate & $\mathrm{Ti}-6 \mathrm{Al}-4 \mathrm{~V}$ & 134 & 20 & 110 & 1.0 & 4420 & 110.3 & 0.3 \\
Hard coating & $\mathrm{MgO}+\mathrm{Al}_{2} \mathrm{O}_{3}$ & 134 & 20 & 110 & 0.02 & 2565 & 50.4 & 0.3 \\
\hline
\end{tabular}

separate the real and imaginary part for residual vector $\mathbf{r}$ in the effort to accurately calculate vibration response in normal coordinate q. Firstly, bring iteration initial value of vibration response in normal coordinate $\widetilde{\mathbf{q}}$ obtained from step (2) into (18); residual vector $\mathbf{r}$ with considering strain dependent mechanical parameters of hard coating can be obtained. Then, by using (24), we can separate its real and imaginary part to get $\overline{\mathbf{r}}$.

(4) Calculate Jacobian Matrix. In this step, because iteration initial value of vibration response, $\widetilde{\mathbf{q}}$, has already been obtained, we can further substitute $\mathbf{q}=\widetilde{\mathbf{q}}$ into (20) and (21) and combine these equations with (12) to get $\partial \mathbf{r} / \partial \mathbf{q}_{R}$ and $\partial \mathbf{r} / \partial \mathbf{q}_{I}$. Next, by bringing the results into (19), we can obtain Jacobian matrix J.

(5) Iteratively Calculate Vibration Response of Composite Plate. Firstly, substitute $\overline{\mathbf{r}}$ obtained from step (3) and Jacobian matrix J obtained from step (4) into (22) to get response increment $\Delta \overline{\mathbf{q}}$ at different iteration calculation times. Then, by using (23) to calculate separation vector of vibration response in normal coordinate $\overline{\mathbf{q}}$, adopt (27) to restore it into complex vector $\mathbf{q}$. In these steps, setting appropriate accuracy factor for iteration calculation $S_{0}$ in (26) is very important; if the resulting residual vector $\mathbf{r}$ does not meet the requirement of $S_{0}$, it is needed to recalculate q. Similar to step (5) in the analysis procedure of nature frequency from Section 4.1, by carefully comparing calculation results, we choose $S_{0}=0.001$ which has been proved to be accurate enough to determine $\mathbf{q}$ with relatively high calculation efficiency. Finally, bring $\mathbf{q}$ to (9), and we can completely obtain vibration response $\mathbf{x}$.

\section{A Study Case}

In this section, a composite plate coated with $\mathrm{MgO}+\mathrm{Al}_{2} \mathrm{O}_{3}$ is taken as a study object, as seen in Figure 3. By considering strain dependence of $\mathrm{MgO}+\mathrm{Al}_{2} \mathrm{O}_{3}$, nature frequencies and vibration responses of coated plate are calculated by FEIM, and its results are compared with linear results for better clarifying analysis effect of nonlinear vibration. Meanwhile, in order to ensure that the finite element model and corresponding cantilever boundary condition are trustworthy, experimental test is conducted on the plate specimen coated with or without hard coating to provide input parameters for theoretical calculation. At last, nonlinear vibration responses containing certain nature frequency under different excitation levels are measured. Through comparing the resulting frequency and response results, the practicability and reliability of FEIM have been verified.
5.1. Nonlinear Vibration Test and Its Results. The geometry parameters and material parameters of the composite plate are listed in Table 1, the substrate plate is Ti-6Al-4V, and the hard coating is $\mathrm{MgO}+\mathrm{Al}_{2} \mathrm{O}_{3}$; its density is already given in [13]. Besides, Young's modulus can be obtained from Figure 1(a) with strain $\varepsilon_{e}=0$ and Poisson is not measured but is assumed to be 0.3 . It should be noted that each geometry parameter is measured by vernier caliper three times and the average is used as the final result, and similar test is done by electron microscope on the thickness of the coating.

In order to accurately test nature frequencies and vibration response of composite plate, the following vibration test system is set up, and its schematic and real test picture can be seen in Figures 3 and 4. The instruments used in the test are as follows: (I) king-design EM-1000F vibration shaker systems; (II) Polytec PDV-100 laser Doppler vibrometer; (III) BK 4514-001 accelerometer; (VI) LMS SCADAS 16-channel mobile front end and Dell notebook computer. In the test set-up, vibration shaker is used to provide base excitation without bringing additional mass and stiffness to the tested plate; laser Doppler vibrometer, mounted to a rigid support, is used to measure the plate velocity at a single point along the excitation direction of vibration shaker, while the base response signal is simultaneously acquired by the accelerometer which is fixed at the clamping fixture. Besides, LMS SCADAS 16-channel data acquisition front end is responsible for recording these signals and Dell notebook computer (with Intel Core i7 $2.93 \mathrm{GHz}$ processor and $4 \mathrm{G} \mathrm{RAM}$ ) is used to operate LMS Test. Lab 10B software and store measured data.

There are two holes with diameter of $9 \mathrm{~mm}$ in the plate which are machined to be clamped by two M8 bolts in the clamping fixture so that clamped-free boundary condition can be simulated. The length, width, and thickness of the clamping fixture are about $200 \mathrm{~mm}, 20 \mathrm{~mm}$, and $20 \mathrm{~mm}$, respectively, so the clamping length of the plate is $20 \mathrm{~mm}$. The laser point is about $22 \mathrm{~mm}$ above the constraint end and the horizontal distance between this point and the left free edge of the plate is about $24 \mathrm{~mm}$. In practice, in order to ensure the tested plate is effectively clamped, the first three nature frequencies are measured under different tightening torque. Through comparison with each other, the best repeatability of frequency values can be reached when the tightening torque is $34 \mathrm{Nm}$, so this torque value is used in the formal test regardless of whether the plate specimen is coated with or without hard coating.

On the one hand, in order to accurately analyze nonlinear vibration response of hard coating composite plate, it is necessary to measure each nature frequency and damping ratio of uncoated plate to provide input parameters for iteration calculation. Firstly, sine sweep test is done on the uncoated plate by selecting sweep frequency range of $0 \sim$ 
TABLE 2: The first 8 nature frequencies and damping ratios of uncoated plate obtained by experimental test.

\begin{tabular}{lcccccccc}
\hline Modal order & 1 & 2 & 3 & 4 & 5 & 6 & 7 & 8 \\
\hline Nature frequency (Hz) & 46.8 & 132.6 & 289.4 & 473.4 & 535.4 & 824.9 & 919.2 & 995.3 \\
Damping ratio (\%) & 0.80 & 0.19 & 0.04 & 0.03 & 0.04 & 0.07 & 0.05 & 0.04 \\
\hline
\end{tabular}

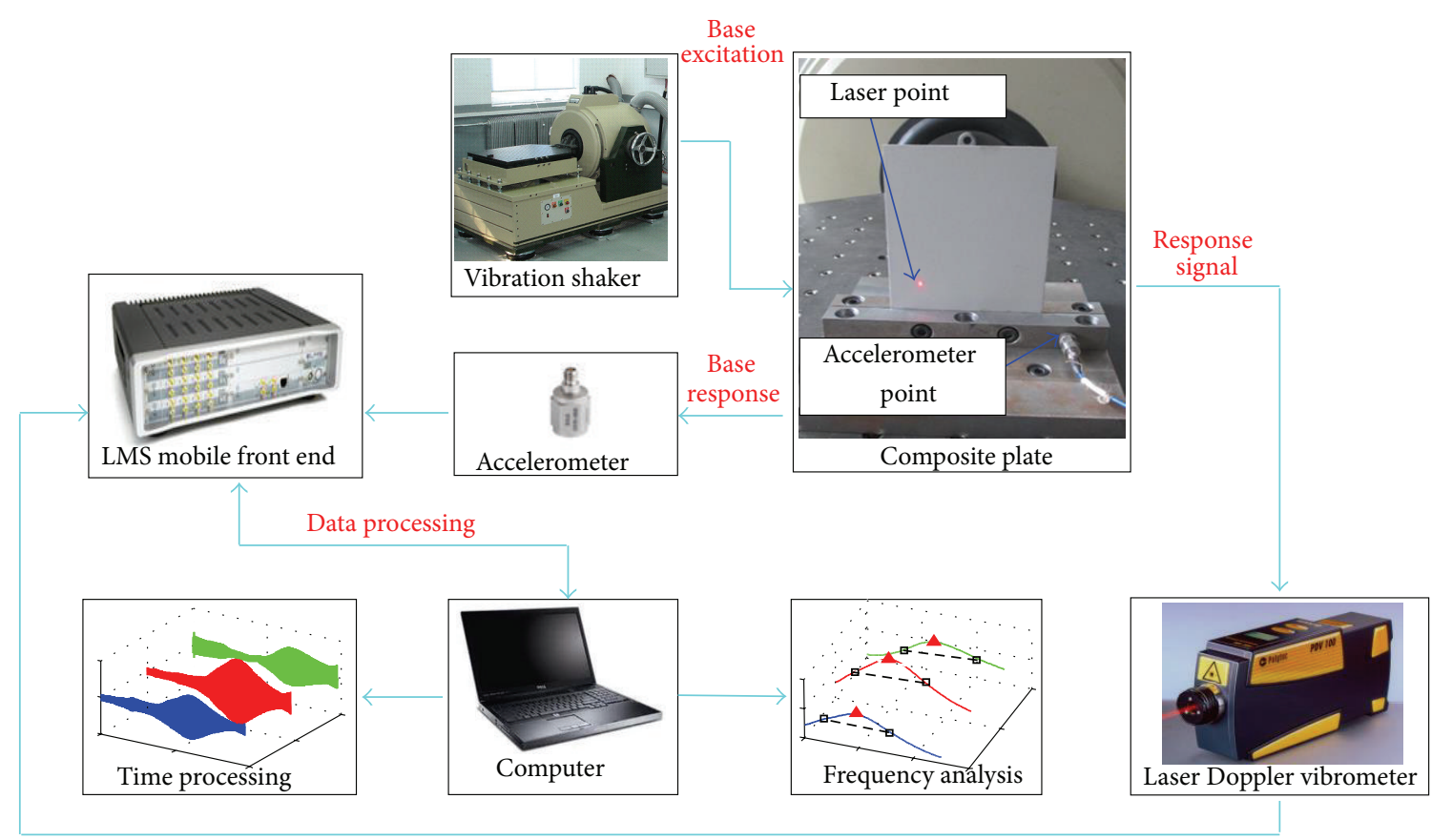

FIGURE 3: Schematic of vibration test system of hard coating composite plate.

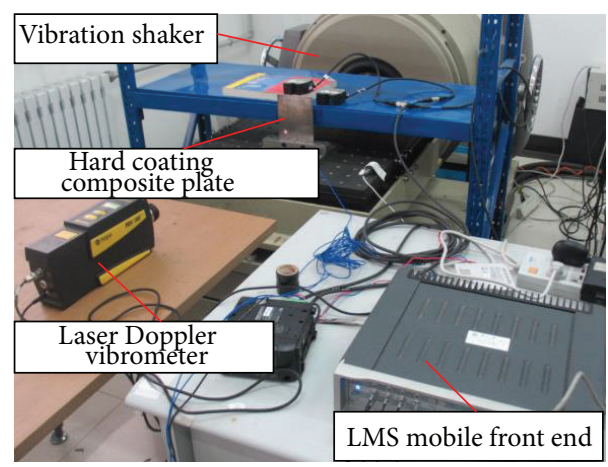

FIGURE 4: Real test picture of vibration test system of hard coating composite plate.

$1000 \mathrm{~Hz}$, base excitation amplitude of $0.1 \mathrm{~g}$, and quick sweep speed of $5 \mathrm{~Hz} / \mathrm{s}$, and consequently the raw sweep signal can be recorded. Next, employ FFT processing technique to get frequency spectrum of the signal, and the first 8 nature frequencies can be roughly determined by identifying the response peak in the related frequency spectrum so that sweep frequency range which contains each imprecise value of nature frequency can be determined.

Because too rapid sweep speed will lead to higher damping values for the coated or uncoated plate, according to the literature [18], the reasonable sweep speed $S(\mathrm{~Hz} / \mathrm{s})$ better meets the following equation in (32), so that the effect of transient vibration in sweep test can be reduced to the lowest level. If the 6th mode of the coated plate is our concern, the required sweep speed $S$ should less than $S_{\max } \approx(824.9 \times$ $0.0007)^{2}=0.33 \mathrm{~Hz}$. But considering sweep efficiency and testing experience in our test series, sweep speed of $1 \mathrm{~Hz} / \mathrm{s}$ is finally chosen to conduct sweep test, and the first 8 nature frequencies and damping ratios of the uncoated plate can be determined by half-power bandwidth technique, as listed in Table 2. Consider

$$
S<S_{\max }=\left(\frac{\eta f_{k}}{2}\right)^{2} \approx \zeta_{k}^{2} f_{k}^{2}
$$

where $f_{k}$ and $\zeta_{k}$ are the $k$ th nature frequency and $k$ th damping ratio of the coated or uncoated plate, respectively, and $\eta$ is the loss factor (approximately two times larger than $\zeta_{k}$ ). These parameters can be measured by half-power bandwidth technique during sweep experiment.

On the other hand, in order to verify the practicability and reliability of FEIM, nature frequencies of coated plate under lower excitation level of $0.3 \mathrm{~g}$ are also obtained and the results are listed in Table 4 (for the convenience of comparing the analysis errors of iteration calculation). And by taking the 6th nature frequency and vibration response as an example, nonlinear vibration test on coated plate is done 
TABLE 3: Nature frequencies of the uncoated plate by FEM calculation.

\begin{tabular}{lcccccccc}
\hline Modal order & 1 & 2 & 3 & 4 & 5 & 6 & 7 & 8 \\
\hline Nature frequency $(\mathrm{Hz})$ & 46.7 & 132.9 & 289.0 & 463.9 & 532.8 & 821.3 & 914.8 & 997.8 \\
\hline
\end{tabular}

TABLE 4: The first 8 nature frequencies of hard coating composite plate under $0.3 \mathrm{~g}$ excitation level obtained by finite element iteration calculation and experimental test.

\begin{tabular}{lcccccccc}
\hline Modal order & 1 & 2 & 3 & 4 & 5 & 6 & 7 \\
\hline Experimental test (Hz) & 47.0 & 132.1 & 287.5 & 470.4 & 536.1 & 823.4 & 918.3 & 997.2 \\
Finite element iteration calculation (Hz) & 46.6 & 132.6 & 288.4 & 463.4 & 530.5 & 819.8 & 911.2 & 995.3 \\
Analysis errors (\%) & 0.85 & -0.38 & -0.31 & 1.49 & 1.04 & 0.43 & 0.99 & -0.11 \\
\hline
\end{tabular}

TABLE 5: The 6th nature frequencies and resonant responses of composite plate under different excitation levels obtained by experimental test and theoretical calculation.

\begin{tabular}{|c|c|c|c|c|c|c|c|c|}
\hline \multirow[b]{2}{*}{$\begin{array}{l}\text { Excitation } \\
\text { level (g) }\end{array}$} & \multicolumn{2}{|c|}{ Experimental test } & \multicolumn{3}{|c|}{ Linear calculation } & \multicolumn{3}{|c|}{ Finite element iteration calculation } \\
\hline & $\begin{array}{l}\text { Nature } \\
\text { frequency } \\
(\mathrm{Hz})\end{array}$ & $\begin{array}{l}\text { Resonant } \\
\text { response } A \\
(\mathrm{~mm} / \mathrm{s})\end{array}$ & $\begin{array}{c}\text { Nature } \\
\text { frequency } \\
(\mathrm{Hz})\end{array}$ & $\begin{array}{l}\text { Resonant } \\
\text { response } B \\
(\mathrm{~mm} / \mathrm{s})\end{array}$ & $\begin{array}{c}\text { Errors } \\
(B-A) / A \\
(\%)\end{array}$ & $\begin{array}{c}\text { Nature } \\
\text { frequency } \\
(\mathrm{Hz})\end{array}$ & $\begin{array}{l}\text { Resonant } \\
\text { response } C \\
(\mathrm{~mm} / \mathrm{s})\end{array}$ & $\begin{array}{c}\text { Errors } \\
(C-A) / A \\
(\%)\end{array}$ \\
\hline 0.3 & 823.4 & 46.7 & 819.8 & 50.2 & 7.5 & 819.8 & 48.2 & 3.2 \\
\hline 0.4 & 823.2 & 62.4 & 819.8 & 65.5 & 5.0 & 819.6 & 63.2 & 1.3 \\
\hline 0.5 & 823.0 & 72.6 & 819.8 & 82.9 & 14.2 & 819.5 & 77.9 & 7.3 \\
\hline 0.6 & 822.9 & 85.6 & 819.8 & 102.5 & 19.7 & 819.3 & 93.2 & 8.9 \\
\hline 0.7 & 822.8 & 95.1 & 819.8 & 117.8 & 23.9 & 819.1 & 104.4 & 9.8 \\
\hline
\end{tabular}

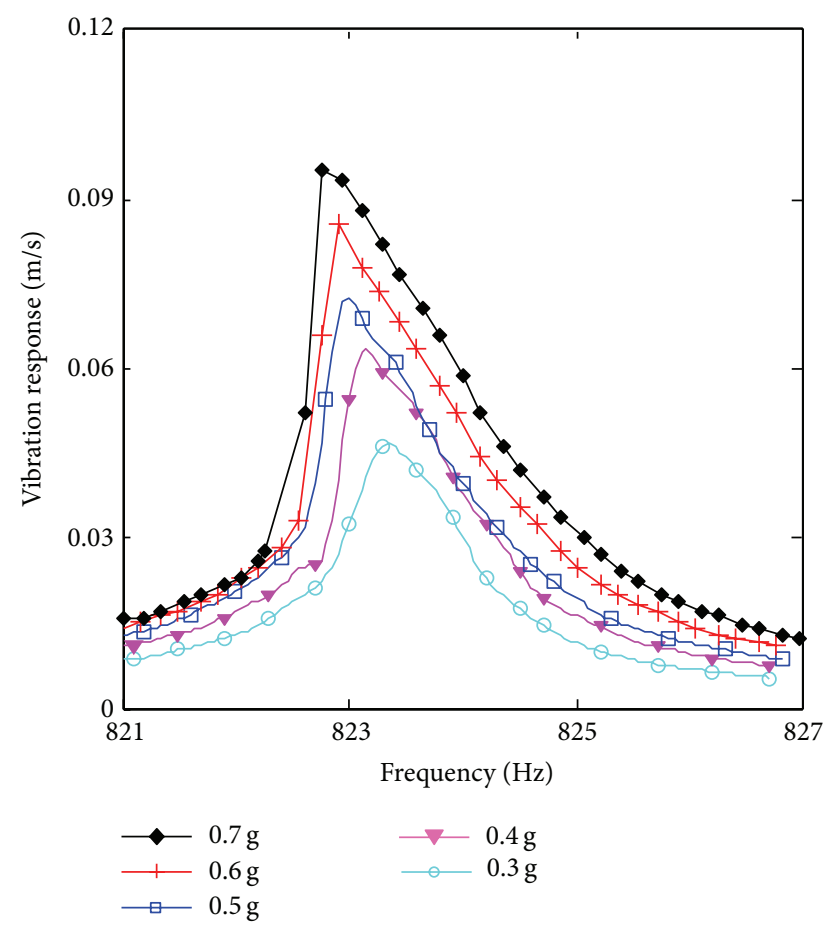

FIGURE 5: Frequency response spectrums containing the 6th nature frequency under different excitation levels obtained by experimental test.

under different base excitation levels. Firstly, set excitation amplitude as total of 5 excitation levels in the software, namely, $0.3 \mathrm{~g}, 0.4 \mathrm{~g}, 0.5 \mathrm{~g}, 0.6 \mathrm{~g}$, and $0.7 \mathrm{~g}$, and then choose much slower sweep speed such as $1 \mathrm{~Hz} / \mathrm{s}$ to accurately obtain the corresponding frequency response spectrum containing the 6th nature frequency under each excitation level, as seen in Figure 5. Consequently, the resulting nature frequencies and resonant responses under different excitation levels can be identified, as listed in Table 5 .

5.2. Nonlinear Vibration Analysis and Its Results. SHELL281 is selected to establish finite element model of the plate with or without hard coating based on ANSYS APDL program, as seen in Figures 6(a) and 6(b), and all the nodes along one side of the plate are constrained in all six degrees of freedom to represent clamped-free boundary condition in the ANSYS software. Besides, the substrate plate and the coating are both meshed with 10 elements along the length or width direction, and the corresponding nodes between them are all coupled together. Firstly, employ uncoated plate model to calculate the first 8 nature frequencies by QR damping or Block Lanczos method, as listed in Table 3. By comparing the resulting frequencies with test results in Table 2, it can be found out that they are very close to each other. Therefore, we can ensure that this model and corresponding cantilever boundary condition are trustworthy. Then, we can use coated plate model to carry out modal analysis by QR damping method and consequently extract mass matrix, damping matrix, stiffness matrix, and external excitation force vector of composite plate. Because the 6th mode of the coated plate is our concern, the related modal shape is also calculated and extracted, as seen in Figure 6(c).

According to the analysis procedure of nature frequency proposed in Section 4.1, with considering strain dependence 


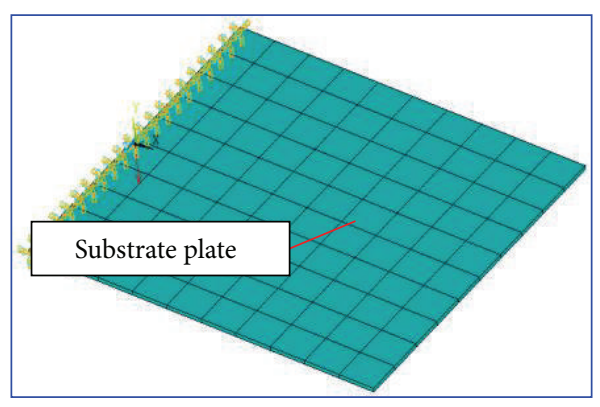

(a) Uncoated plate model

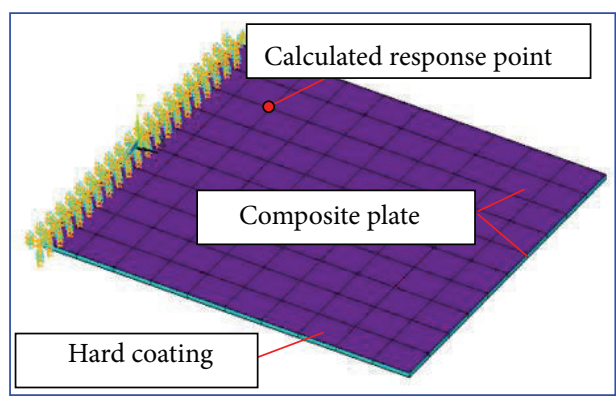

(b) Coated plate model

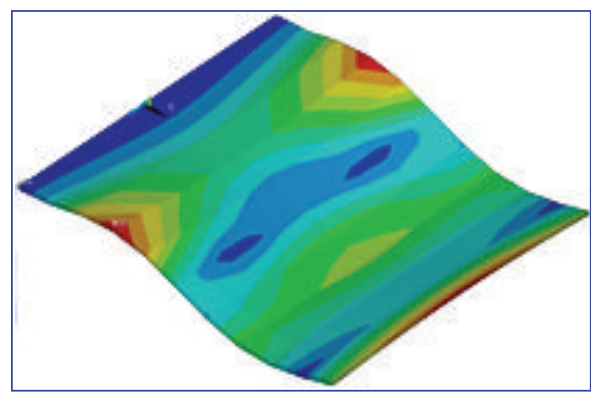

(c) The 6th modal shape of the coated plate

FIGURE 6: Finite element model and modal shape of hard coating composite plate.

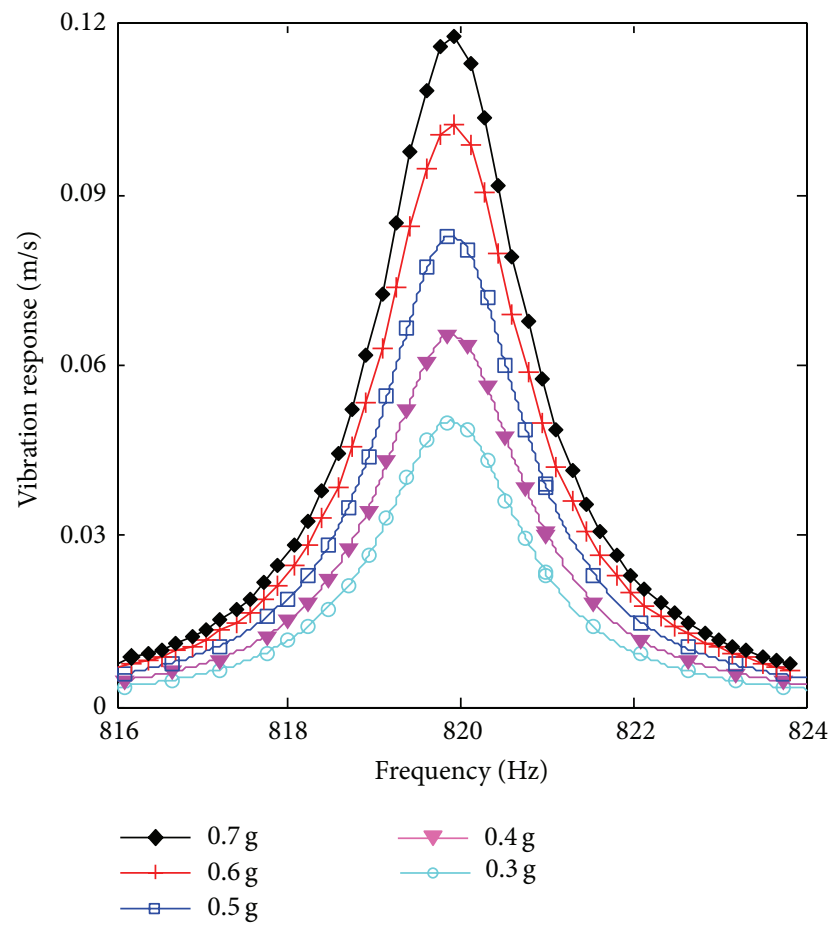

Figure 7: The 6th frequency response spectrums of hard coating composite plate obtained by linear calculation method.

of $\mathrm{MgO}+\mathrm{Al}_{2} \mathrm{O}_{3}$, the first 8 nature frequencies of coated plate are calculated by FEIM based on the MATLAB program (under $0.3 \mathrm{~g}$ excitation level similar to the one in experimental test), as listed in Table 4. Besides, the corresponding analysis errors of iteration calculation from 1st to 8th mode are obtained and listed in the same table.

After finishing calculation work of nature frequencies of coated plate, we can further iteratively calculate its responses based on the analysis procedure of vibration response proposed in Section 4.2. Similar to experimental test, including the same excitation levels $(0.3 \mathrm{~g}, 0.4 \mathrm{~g}, 0.5 \mathrm{~g}, 0.6 \mathrm{~g}$, and $0.7 \mathrm{~g})$ and the same response point, nonlinear vibration responses containing the 6 th nature frequency under different excitation levels are obtained, and the resulting frequencies and resonant responses are listed in Table 5. Then, for better clarifying analysis effect of nonlinear vibration, the related linear calculation results under the above excitation levels are also given in the same table (in this circumstances, storage modulus $E_{c}^{\prime}\left(\varepsilon_{e}\right)$ and loss modulus $E_{c}^{\prime \prime}\left(\varepsilon_{e}\right)$ are linear in (4) and (5) with equivalent strain $\varepsilon_{e}=0$ ), and consequently analysis error results between these two theoretical calculation method and experimental method are obtained and listed in Table 5. At last, by applying finite element iteration calculation as well as linear calculation method, frequency response spectrums in the vicinity of the 6th resonant response are plotted with frequency interval of $0.01 \mathrm{~Hz}$ in the range of $816 \sim 824 \mathrm{~Hz}$, and the resulting spectrums can be seen in Figures 7 and 8.

5.3. Result Analysis and Discussion. We analyze and discuss the results as follows:

(1) As can be seen from Table 4, the first 8 nature frequencies of coated plate under $0.3 \mathrm{~g}$ excitation level obtained by finite element iteration calculation and experimental test are in good agreement and the 


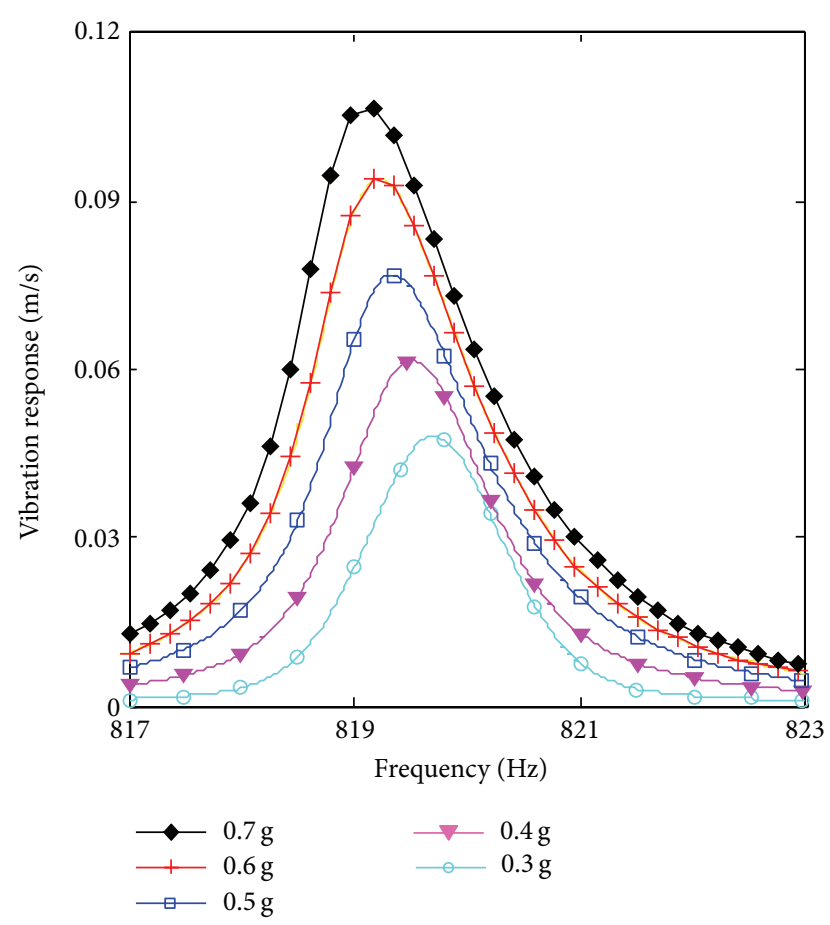

Figure 8: The 6th frequency response spectrums of hard coating composite plate obtained by finite element iteration method.

maximum analysis errors are less than $2 \%$. Therefore, this nonlinear calculation method can be used to analyze nature frequency of hard coating composite plate with high preciseness.

(2) As can be seen from Table 5, the resulting 6th nature frequencies obtained under different excitation levels by finite element iteration calculation can comply with the same rule discovered in experimental test; that is, nature frequency of coated plate will decrease with the increase of base excitation level, which shows soft stiffness nonlinear or "strain softening." Additionally, the results also show that the resonant responses obtained by iteration calculation are relatively lower than the ones obtained by linear calculation, and linear calculation errors are larger than the corresponding errors of iteration calculation. For example, the maximum error of linear calculation is about $24 \%$ while the one of iteration calculation is less than $10 \%$, which are within an acceptable range. Therefore, the reliability of FEIM has been verified, which can be used to analyze nonlinear vibration response of composite plate with considering strain dependent mechanical parameters of hard coating.

(3) However, the maximum error of iteratively calculated resonant response reaches $10 \%$, and the amplitude differences in frequency response spectrums between the experiment and theoretical calculation from Figures 5 and 8 are still existed, which might be due to the following reasons: (I) the laser point in experimental test and response point chosen in theoretical calculation are not closely coincident; (II) the nonlinearities of hard coating composite plate are caused by not only strain dependence of the coating, but also nonlinearity of clamping fixture, shear deformation of the uncoated plate, and other factors, which are not considered in the above nonlinear vibration analysis procedure; (III) comparing with the real values, there are some errors in geometry parameters and material parameters used in theoretical calculation, for example, Young's modulus, loss modulus and the thickness of the coating, and so forth.

\section{Conclusions}

This research proposes finite element iteration method to analyze nonlinear vibration of hard coating thin plate, and experimental test is used to verify the practicability and reliability of this nonlinear calculation method. Based on the analysis and experimental results, the following conclusions can be drawn.

(1) Polynomial method can be used to characterize the storage and loss modulus of coating material, which are mainly responsible for nonlinearity of hard coating composite plate.

(2) FEIM combines the advantages of ANSYS APDL program and self-designed MATLAB program with the following analysis techniques: (I) firstly write APDL program to calculate and extract mass matrix, damping matrix, stiffness matrix, and external excitation force vector of finite element model of composite plate; (II) secondly write finite element iteration program based on MATLAB to calculate equivalent strain of each element, and consequently get complex modulus by the known mechanical parameters of hard coating obtained by polynomial method; (III) finally obtain complex stiffness matrix in normal coordinate, and thus nature frequency and vibration response can be iteratively calculated by setting appropriate iteration termination condition.

(3) FEIM is an effective theoretical analysis method to analyze nonlinear dynamics mechanism of hard coating composite plate because the calculation results are in good agreement with the experimental results. For example, the maximum analysis errors of the first 8 nature frequencies is less than $2 \%$ and the errors of the 6 th resonant response under different excitation levels are less than $10 \%$. Besides, the iteratively calculated results can comply with the same rule discovered in experimental test; that is, nature frequency of composite plate will decrease with the increase of external excitation level, which shows soft stiffness nonlinear or "strain softening." 


\section{Conflict of Interests}

The authors declare that there is no conflict of interests regarding the publication of this paper.

\section{Acknowledgment}

This study was supported by the National Nature Science Foundation of China, 51375079.

\section{References}

[1] H.-Y. Yen and M.-H. Herman Shen, "Passive vibration suppression of beams and blades using magnetomechanical coating," Journal of Sound and Vibration, vol. 245, no. 4, pp. 701-714, 2001.

[2] G. Gregori, L. Lì, J. A. Nychka, and D. R. Clarke, "Vibration damping of superalloys and thermal barrier coatings at hightemperatures," Materials Science and Engineering A, vol. 466, no. 1-2, pp. 256-264, 2007.

[3] G. Y. Du, D. C. Ba, Z. Tan, W. Sun, K. Liu, and Q. K. Han, "Vibration damping performance of ZrTiN coating deposited by arc ion plating on TC4 Titanium alloy," Surface and Coatings Technology, vol. 229, pp. 172-175, 2013.

[4] F. Ivancic and A. Palazotto, "Experimental considerations for determining the damping coefficients of hard coatings," Journal of Aerospace Engineering, vol. 18, no. 1, pp. 8-17, 2005.

[5] C. Blackwell, A. Palazotto, T. J. George, and C. J. Cross, “The evaluation of the damping characteristics of a hard coating on titanium," Shock and Vibration, vol. 14, no. 1, pp. 37-51, 2007.

[6] J. E. Hansel, The influence of thickness on the complex modulus of air plasma sprayed ceramic blend coatings [M.S. thesis], Wright State University, Dayton, Ohio, USA, 2008.

[7] N. Tassini, S. Patsias, and K. Lambrinou, "Ceramic coatings: a phenomenological modeling for damping behavior related to microstructural features," Materials Science and Engineering A, vol. 442, no. 1-2, pp. 509-513, 2006.

[8] J. Green and S. Patsias, "A preliminary approach for the modeling of a hard damping coating using friction elements," in Proceedings of 7 th National Turbine Engine High Cycle Fatigue Conference, pp. 1-9, Palm Beach Gardens, Fla, USA, 2002.

[9] P. J. Torvik, "A slip damping model for plasma sprayed ceramics," Journal of Applied Mechanics, vol. 76, no. 6, Article ID 061018, 8 pages, 2009.

[10] R. K. A. Al-Rub and A. N. Palazotto, "Micromechanical theoretical and computational modeling of energy dissipation due to nonlinear vibration of hard ceramic coatings with microstructural recursive faults," International Journal of Solids and Structures, vol. 47, no. 16, pp. 2131-2142, 2010.

[11] S. Patsias, C. Saxton, and M. Shipton, "Hard damping coatings: an experimental procedure for extraction of damping characteristics and modulus of elasticity," Materials Science and Engineering A, vol. 370, no. 1-2, pp. 412-416, 2004.

[12] P. J. Torvik, "Determination of mechanical properties of nonlinear coatings from measurements with coated beams," International Journal of Solids and Structures, vol. 46, no. 5, pp. 10661077, 2009.

[13] S. A. Reed, A. N. Palazotto, and W. P. Baker, "An experimental technique for the evaluation of strain dependent material properties of hard coatings," Shock and Vibration, vol. 15, no. 6, pp. 697-712, 2008.
[14] E. M. Hernandez and D. Bernal, "Iterative finite element model updating in the time domain," Mechanical Systems and Signal Processing, vol. 34, no. 1-2, pp. 39-46, 2013.

[15] Y. Hu, Q. Di, W. Zhu, Z. Chen, and W. Wang, "Dynamic characteristics analysis of drillstring in the ultra-deep well with spatial curved beam finite element," Journal of Petroleum Science and Engineering, vol. 82-83, pp. 166-173, 2012.

[16] D. Soares Jr., "An optimised FEM-BEM time-domain iterative coupling algorithm for dynamic analyses," Computers \& Structures, vol. 86, no. 19-20, pp. 1839-1844, 2008.

[17] S. Filippi and P. J. Torvik, "A methodology for predicting the response of blades with nonlinear coatings," Journal of Engineering for Gas Turbines and Power, vol. 133, no. 4, Article ID 042503, 2011.

[18] P. J. Torvik, "On estimating system damping from frequency response bandwidths," Journal of Sound and Vibration, vol. 330, no. 25, pp. 6088-6097, 2011. 

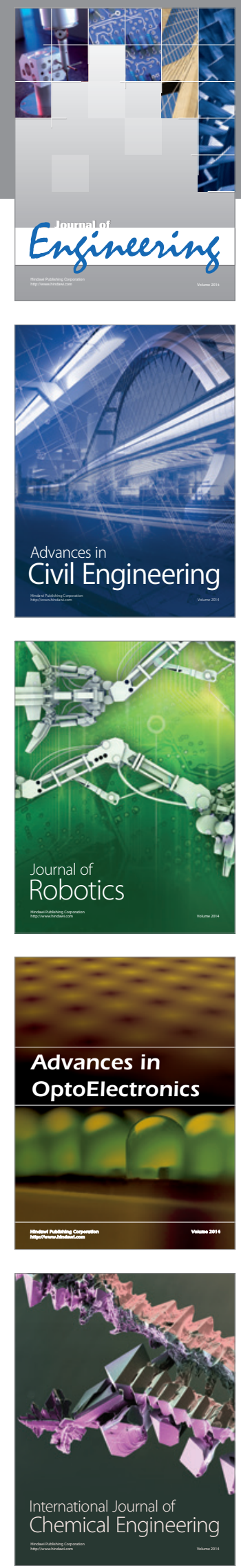

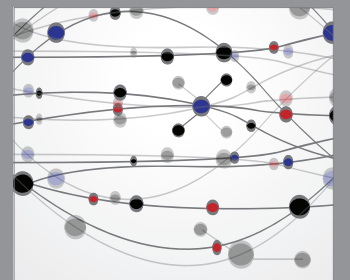

The Scientific World Journal
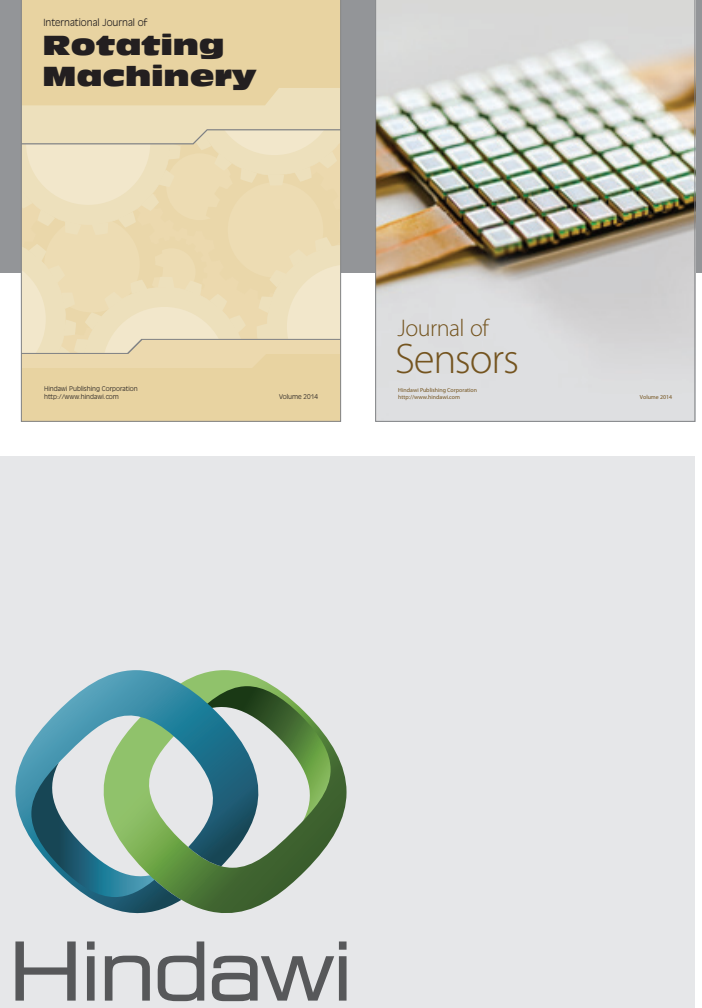

Submit your manuscripts at http://www.hindawi.com
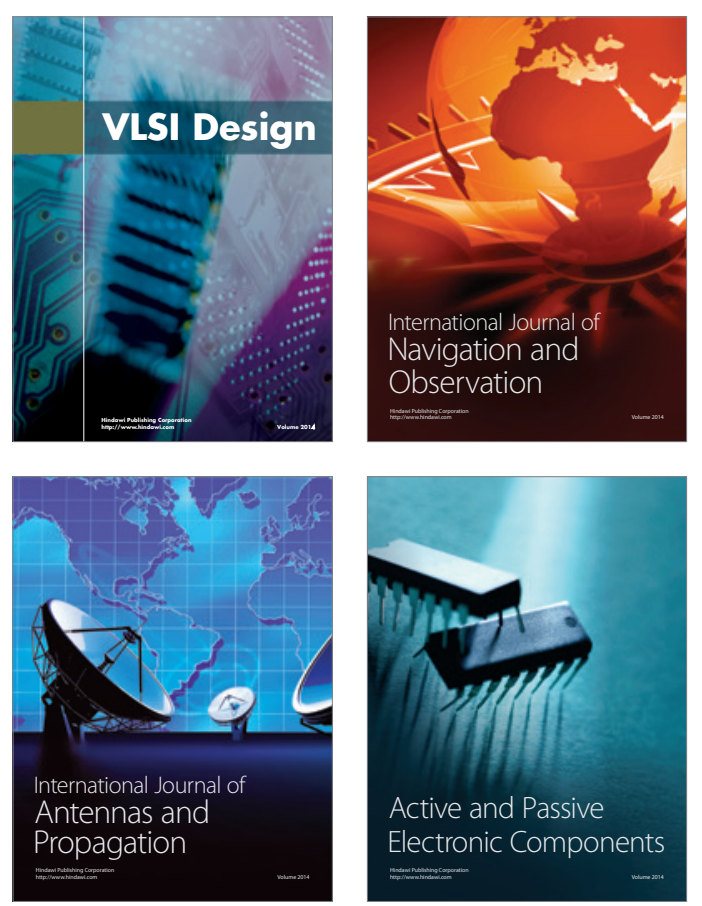
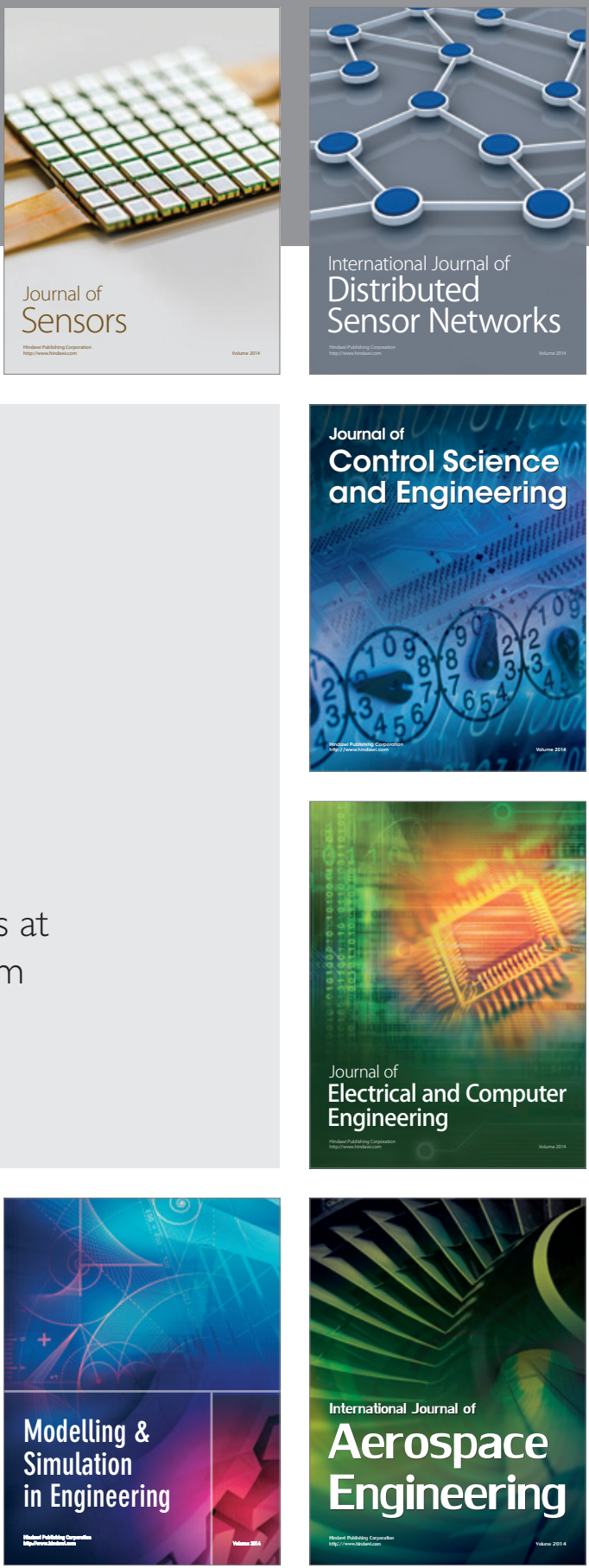

Journal of

Control Science

and Engineering
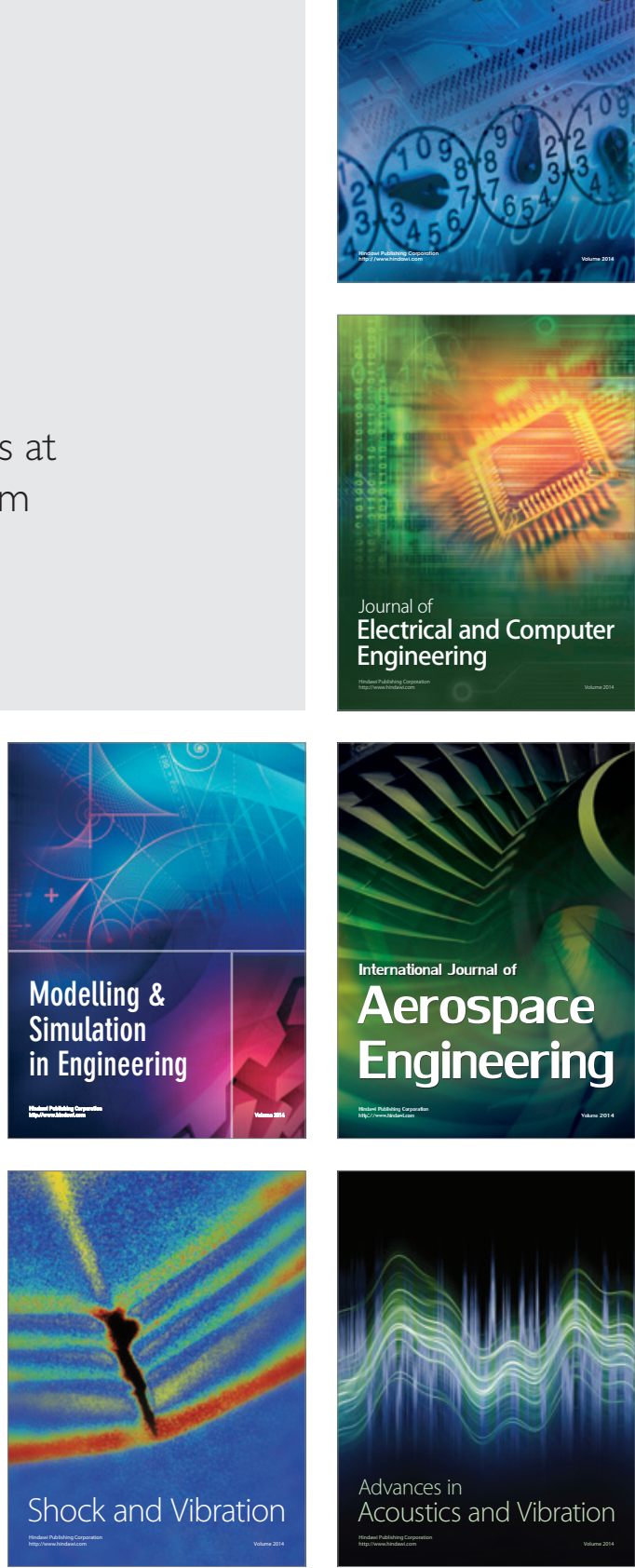